

\title{
Synthesis of 3-Heteroaryloxindoles through $t$-BuOCl-Mediated Oxidation of 3-Heteroarylindoles
}

\author{
Marco Baroni, ${ }^{a}$ Giordano Lesma, ${ }^{\mathrm{b}}$ Letizia Puleio, ${ }^{\mathrm{a}}$ Alessandro Sacchetti, ${ }^{\mathrm{c}}$ Alessandra Silvani, ${ }^{\mathrm{b}}$ Marco Zanchet ${ }^{\mathrm{a}}$ \\ a Sanofi-Aventis, Centro Ricerche Sanofi-Midy, Via G. Sbodio 2, 20134 Milano, Italy \\ b Dipartimento di Chimica Organica e Industriale, Università degli Studi di Milano, Via G. Venezian 21, 20133 Milano, Italy \\ Fax +39(02)50314078; E-mail: alessandra.silvani@unimi.it \\ c Politecnico di Milano, Dipartimento di Chimica, Materiali ed Ingegneria Chimica 'Giulio Natta', Via Mancinelli 7, 20131 Milano, Italy \\ Received 23 July 2010
}

\begin{abstract}
The oxidation of 3-heteroarylindoles to the corresponding oxindoles with $t$-butyl hypochlorite has been investigated. Under carefully adjusted conditions, preparative scale of desired products can be achieved. Two competing pathways seem to contribute to the reaction mechanism, affording 3-heteroaryloxindoles bearing hydrogen or chlorine at $\mathrm{C} 3$, depending on stereoelectronic factors. The present methodology appears also generally applicable for the preparation of simple 3-aryloxindoles.
\end{abstract}

Key words: indole, oxindole, $t$ - $\mathrm{BuOCl}$, oxidation, heterocycles

Oxindole-containing heterocycles, particularly those substituted at the $\mathrm{C} 3$ position, are commonly encountered in natural products ${ }^{1}$ and pharmaceutical compounds. ${ }^{2}$ They display a wide range of biological properties, including antitumoral ${ }^{3}$ and antiviral ${ }^{4}$ activities.

Moreover, diverse oxindole derivatives are used as nonpeptide scaffolds ${ }^{5}$ in the search for peptidomimetics either as enzyme inhibitors or as ligands of G-protein coupled receptors. ${ }^{6}$ For instance, the oxindole framework is the essential feature of orally active nonpeptide argininevasopressin receptor antagonists, ${ }^{7}$ of growth hormone secretagogue (ghrelin) receptors agonists, ${ }^{8}$ and of a potent gastrin/CCK-B receptor antagonist. ${ }^{9}$ As a consequence, the selective functionalization at $\mathrm{C} 3$ by alkyl, alkenyl, aryl, or heteroaryl groups of $\mathrm{N}$-unsubstituted oxindoles has been a longstanding issue. ${ }^{10}$

In the course of a program directed toward the search for new pharmaceutically relevant oxindole scaffolds, ${ }^{11}$ we became interested in developing the synthesis of several unprecedented 3-amino-3'-heteroaryloxindoles, especially those bearing chlorine on the aromatic ring. Preliminary attempts were directed to apply a few synthetic methodologies that are known for the preparation 3-amino-3'-aryloxindoles, such as Grignard addition to isatine ${ }^{12}$ or intramolecular Friedel-Crafts cyclization onto $\alpha$-hydroxyacetanilides, ${ }^{13}$ according to Scheme 1 . Widening the scope to 3-amino-3'-heteroaryloxindoles, we could point out that, unfortunately, these approaches proved to be quite often not applicable. In the case of Grignard addition, a limited range of organomagnesium heterocyclic

SYNTHESIS 2010, No. 23, pp 4075-4081

Advanced online publication: 07.10.2010

DOI: 10.1055/s-0030-1258289; Art ID: P12010SS

(c) Georg Thieme Verlag Stuttgart · New York compounds can be achieved. Reaction at the $\mathrm{C} 3$ isatine position with organolithium derivatives is moreover highly incompatible with halogenated isatine cores. On the other hand, the strongly acidic conditions and high temperatures required for Friedel-Crafts cyclization limit the range of tolerated functional groups. Also application of a palladium-catalyzed variant of the Friedel-Crafts procedure, starting from properly functionalized $\alpha$-chloroacetanilides, ${ }^{14}$ proved to be not applicable to obtain 3heteroaryloxindoles, since nontrivial synthetic sequences are required to prepare the appropriate precursors for the reaction.

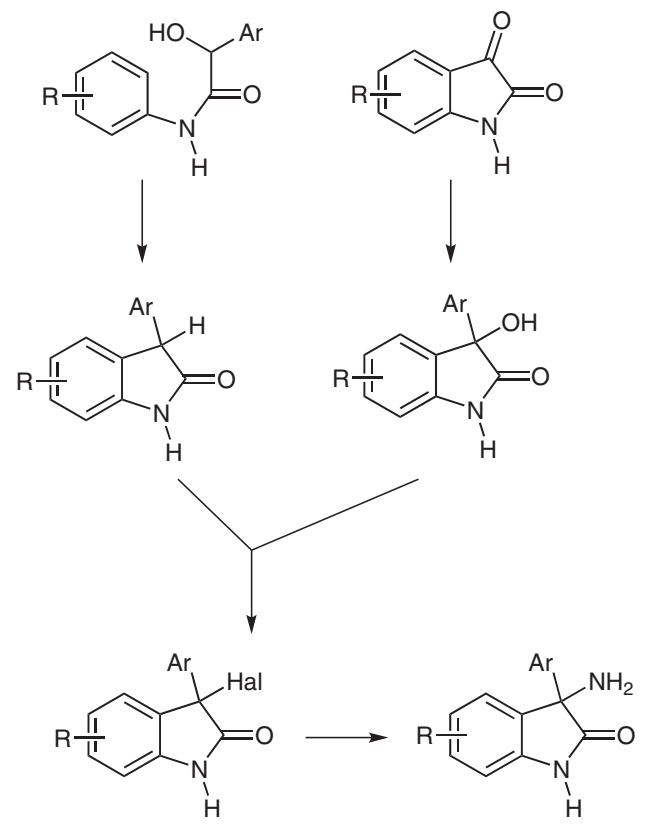

Scheme 1 Some approaches to 3-amino-3'-aryloxindoles

Therefore, our efforts turned toward setting up an alternative approach to 3-heteroaryloxindoles, based on the oxidation of the corresponding 3-heteroarylindoles by treatment with electrophilic halogenating agents. Subsequent conversion into 3-amino-3'-heteroaryloxindoles would be straightforward. ${ }^{15}$

While many methods exist for the construction of oxindole from non-indole precursors, fewer options are available for the direct conversion of indoles into the corresponding oxindoles. ${ }^{16}$ These methods involve often 
harsh conditions ${ }^{17}$ or aqueous enzymatic systems ${ }^{18}$ for the oxidation step and their applicability is sometimes restricted to a few substrates. To the best of our knowledge, this conversion has never been applied for the synthesis of 3-heteroaryloxindoles.

In our search for an efficient protocol, we drew our inspiration from the well-known oxidative rearrangement of indoles to oxindoles upon treatment with electrophilic halogenating agents, such as tert-butyl hypochlorite. This conversion has been investigated in simple indoles for several decades ${ }^{19}$ and it has also found recent use in natural products chemistry. ${ }^{20}$ The generally accepted mechanism is based on the key conversion of a 2,3-disubstituted indole into the corresponding 3-haloindolenine and also includes the migration of a $\mathrm{R}$ group from $\mathrm{C} 2$ to $\mathrm{C} 3$, affording the final 3,3'-disubstituted oxindole.

It was reasoned that tert-butyl hypochlorite could be a useful reagent also for our scope and so, in a first step, the preparation of a wide range of 3-heteroarylindoles as substrates was envisaged, with the aim of studying the potential applicability of this kind of oxidative process. Preparation of 3-heteroarylindoles was performed according to the general protocol reported in Table $1 .{ }^{21}$

The required 3-bromoindoles 1a,b were prepared according to the literature. ${ }^{22}$ Starting from $\mathbf{1 a}, \mathbf{b}$, halogen-metal exchange with $\mathrm{BuLi}$ at $-78{ }^{\circ} \mathrm{C}$ achieved highly selective 3-lithiation. Transmetalation of the resulting 3-lithioindoles with $\mathrm{B}(\mathrm{O}-i \mathrm{Pr})_{3}$ afforded indol-3-ylboronic acids 2a,b in satisfactory yields. ${ }^{23}$ With the obtained electronrich indol-3-ylboronic acids $\mathbf{2 a}, \mathbf{b}$, the coupling with bromide heterocycles, under the Suzuki-Miyaura conditions was then examined. ${ }^{24}$ The desired cross-coupling products $\mathbf{3 a}-\mathbf{j}$ were readily obtained in a range of moderate to quantitative yields (Table 1).

With 3-heteroarylindoles in hand, the oxidation to the corresponding oxindoles (Table 2) was studied. To a freshly prepared $1 \mathrm{M}$ solution of $t$ - $\mathrm{BuOCl}$ in $\mathrm{CH}_{2} \mathrm{Cl}_{2}$ (1 equiv) was added a $0.3 \mathrm{M} \mathrm{CH}_{2} \mathrm{Cl}_{2}$ solution of 3a. After consumption of the starting material, visualized by TLC, the solvent was removed under a nitrogen stream and the residue was dissolved in a 2:1 1,4-dioxane-aq $3 \mathrm{~N} \mathrm{H}_{2} \mathrm{SO}_{4}$ solution. After two hours, only the corresponding 2-chloroindole 4a was recovered quantitatively (Table 2, entry 1). Treatment of $4 \mathbf{a}$ with one equivalent of $t-\mathrm{BuOCl}$ afforded 6a in high yield (entry 2). Reasoning on the reaction mechanism, it was deduced that more $t$ - $\mathrm{BuOCl}$ would be necessary in order to carry out the oxidation and so the reaction on $\mathbf{3 a}$ with two equivalents of $t$ - $\mathrm{BuOCl}$ (entry 3) was planned. In this case 3-chlorooxindole 6a was isolated, together again with $20 \%$ of 2 -chloroindole $4 a$. The best result was then achieved with three equivalents of $t$ $\mathrm{BuOCl}$, the reaction affording 3-chlorooxindole $\mathbf{6 a}$ in almost quantitative yield (entry 4 ). With substrates $\mathbf{3 b}-\mathbf{e}$ the corresponding 3-chlorooxindoles were produced, without recovery of 2-chloroindole, already with two equivalents of $t$-BuOCl. Attempts to get higher yields employing more oxidant were not successful, since increasing
Table 1 Synthesis of 3-Heteroarylindoles $\mathbf{3} \mathbf{a}-\mathbf{j}^{\mathrm{a}}$

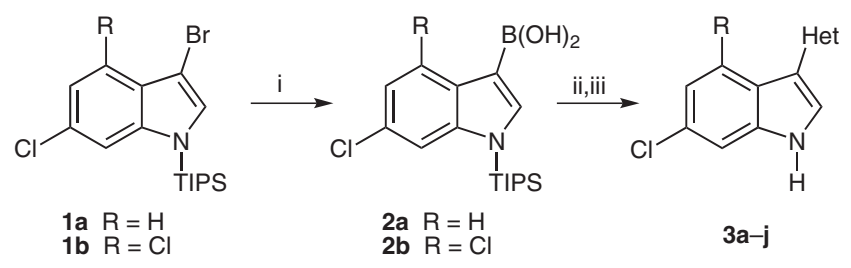

1a

${ }^{a}$ Reaction conditions: (i) BuLi (1.6 M; 1.1 equiv), $\mathrm{B}(\mathrm{O} i-\mathrm{Pr})_{3}(3$ equiv), THF, $-78{ }^{\circ} \mathrm{C}$; (ii) $\mathrm{HetBr}\left(1\right.$ equiv), $\mathrm{Pd}\left(\mathrm{PPh}_{3}\right)_{4}(0.05$ equiv), toluene- $\mathrm{MeOH}$, aq $\mathrm{Na}_{2} \mathrm{CO}_{3}(2 \mathrm{M})$, reflux; (iii) $\mathrm{Bu}_{4} \mathrm{~N}^{+} \mathrm{F}^{-}(1 \mathrm{M}$ in THF), THF, $0{ }^{\circ} \mathrm{C}$.

amounts of chlorinated by-products started to appear (entries 5-8).

The reaction of substrate $\mathbf{3 f}$, bearing an additional chlorine substituent at $\mathrm{C} 4$ of the indole nucleus with one equivalent of $t$ - $\mathrm{BuOCl}$ afforded a mixture of 2-chloroindole $4 \mathbf{f}(53 \%)$ and oxindole $5 \mathbf{f}(38 \%)$, suggesting that a slightly different reaction pathway would apply in this case (entry 9). In fact, when two equivalents of $t$ - $\mathrm{BuOCl}$ 
Table 2 Synthesis of 3-Heteroaryloxindoles 5 and $\mathbf{6}^{\mathrm{a}}$

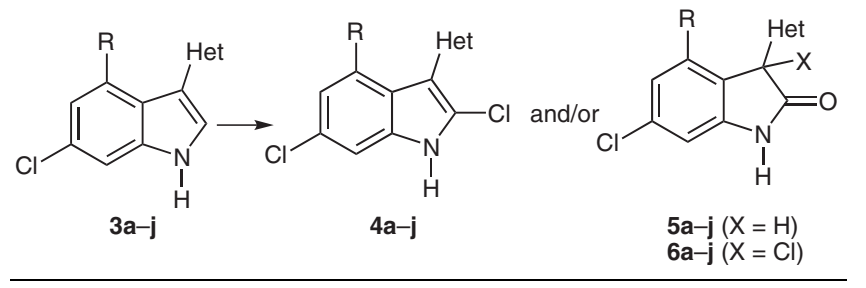

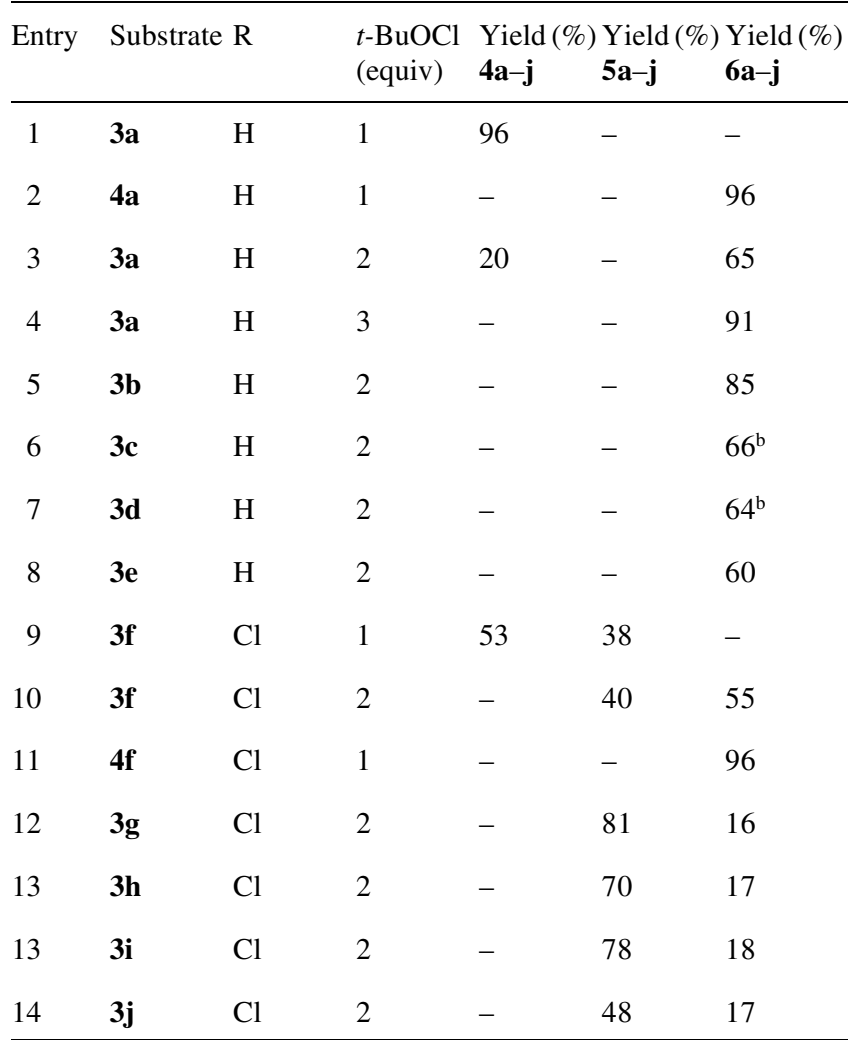

a Reaction conditions: (i) $1 \mathrm{M} t$ - $\mathrm{BuOCl}$ in $\mathrm{CH}_{2} \mathrm{Cl}_{2}, \mathrm{CH}_{2} \mathrm{Cl}_{2}$, r.t.; (ii) then dioxane-aq $3 \mathrm{~N} \mathrm{H}_{2} \mathrm{SO}_{4}(2: 1)$.

${ }^{\mathrm{b}}$ Some traces of halogenated by-products were detected.

were employed, almost the same amount of $\mathbf{5 f}$ was obtained, together with 55\% of 3-chlorooxindole $\mathbf{6 f}$ (entry 10). Also in this case, quantitative conversion of 2-chloroindole $4 \mathbf{f}$ into 3 -chlorooxindole $\mathbf{6} \mathbf{f}$ was realized with one equivalent of $t$ - $\mathrm{BuOCl}$ (entry 11). Finally, starting from substrates $\mathbf{3} \mathbf{g}-\mathbf{j}$, high conversions into the corresponding oxindoles were always observed, albeit as mixtures of compounds 5 and 6 (entries 12-15).

Reasoning on the reaction mechanism and in accordance with the well-known ${ }^{25}$ oxidative rearrangement of indoles to oxindoles, promoted by electrophilic halogenating agents, the first chlorination step should afford preferentially the 3-chloroindolenine derivative 7 (Scheme 2, path a), which is the precursor of the oxindole 5 . From our results, however, it was deduced that the presence of a heteroaryl substituent at $\mathrm{C} 3$ affects deeply the outcome of this reaction, leading primarily the electrophilic attack of $t$ - $\mathrm{BuOCl}$ at $\mathrm{C} 2$, probably for both steric and electronic reasons (path b). In particular, electronic effects would play a key role, due to the extensive conjugation of the all coplanar aromatic ring system. When an additional equiva- lent of $t$ - $\mathrm{BuOCl}$ was added, the initially formed 2chloroindole 4 was converted into the corresponding 3chlorooxindole $\mathbf{6}$, via the dichloroindolenine derivative $\mathbf{8}$. In the case of substrates $\mathbf{3 f}-\mathbf{j}$ bearing an additional chlorine substituent at $\mathrm{C} 4$, the effect of the presence of the substituent on $\mathrm{C} 3$ seems to fade out, probably also due to the lost of coplanarity imposed by steric hindrance of the chlorine at $\mathrm{C} 4$. As a consequence, the competitive $\mathrm{C} 3$ electrophilic attack takes place all along, affording directly oxindoles 5 , together with 3-chlorooxindoles 6 . In these cases, slight differences in the ratio between yields of compounds 5 and $\mathbf{6}$ could be addressed to further less predictable stereoelectronic effects.

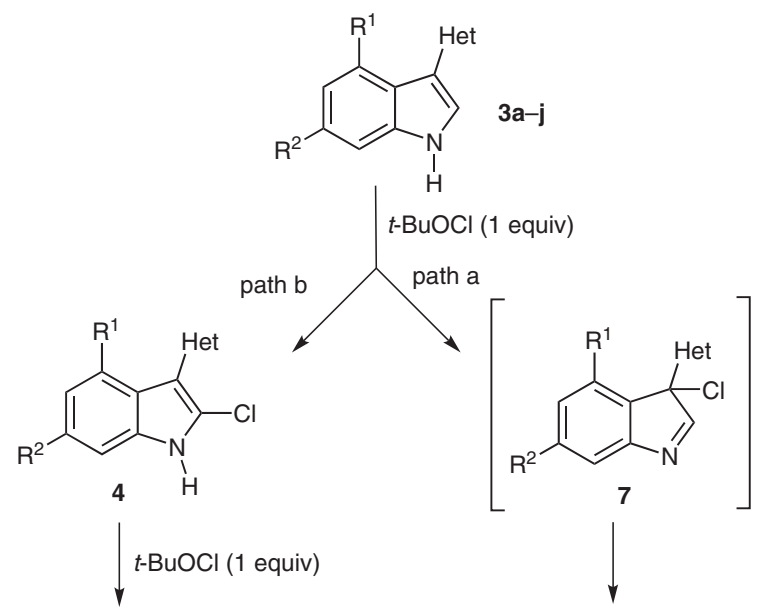<smiles>[R7]c1cc([R])c2c(c1)NC(=O)C2(Cl)Cl</smiles>

6<smiles>[R]c1cc([R])c2c(c1)NC(=O)C2CC</smiles>

Scheme 2 Proposed mechanism for the reaction of 3-heteroarylindoles $3 \mathbf{a}-\mathbf{j}$ with $t$ - $\mathrm{BuOCl}$

In summary, by means of a careful adjustment of the reaction conditions, the synthesis of 3-heteroaryloxindoles by $t$-BuOCl-mediated oxidation of 3-heteroarylindoles was found to be general. It can be applied to a variety of functionalized indoles yielding products, which are at this time hardly achievable by other methods. It should be highlighted that both oxindoles 5 and 3-chlorooxindoles 6 proved to be well suited for subsequent transformation towards 3-amino-3'-heteroaryloxindoles.

All solvents were distilled and properly dried, when necessary, prior to use. All chemicals were purchased from commercial sources and used directly, unless indicated otherwise. All reactions were run un- 
der $\mathrm{N}_{2}$, unless otherwise indicated. All reactions were monitored by TLC on precoated silica gel $60 \mathrm{~F} 254$; spots were visualized with UV light or by treatment with $1 \%$ aq $\mathrm{KMnO}_{4}$. Products were purified by flash chromatography (FC) on silica gel 60 (230-400 mesh). ${ }^{1} \mathrm{H}$ and ${ }^{13} \mathrm{C}$ NMR spectra were recorded using 300 and $400 \mathrm{MHz}$ spectrometers. Chemical shifts $(\delta)$ are expressed in ppm relative to TMS at $\delta=0$ for ${ }^{1} \mathrm{H} \mathrm{NMR}$ and to $\mathrm{CDCl}_{3}$ at $\delta=77.16$ for ${ }^{13} \mathrm{C}$ NMR spectroscopy. High-resolution MS spectra were recorded using an FT-ICR (Fourier Transform Ion Cyclotron Resonance) instrument, equipped with ESI source, or a standard MS instrument, equipped with EI source. IR spectra were recorded using an FTIR instrument.

\section{3-Heteroarylindoles 3; 6-Chloro-3-(5-methylpyridin-2-yl)-1H-} indole (3a); Typical Procedure

To a solution of 2-bromo-5-methylpyridine $(172 \mathrm{~g} / \mathrm{mol}, 2 \mathrm{~g}, 11.6$ mmol, 1 equiv) and [6-chloro-1-(triisopropylsilyl)- $1 H$-indol-3yl]boronic acid $(\mathbf{2 a} ; 351 \mathrm{~g} / \mathrm{mol}, 4 \mathrm{~g}, 11.6 \mathrm{mmol}, 1$ equiv) in a toluene- $\mathrm{MeOH}(4: 1)$ solution $(50 \mathrm{~mL})$ were added aq $2 \mathrm{M} \mathrm{Na}_{2} \mathrm{CO}_{3}(9$ $\mathrm{mL})$, and $\mathrm{Pd}\left(\mathrm{PPh}_{3}\right)_{4}(1155.5 \mathrm{~g} / \mathrm{mol}, 670 \mathrm{mg}, 0.6 \mathrm{mmol}, 0.05$ equiv). The mixture was heated at reflux under stirring for $4 \mathrm{~h}$, cooled, and then partitioned between EtOAc $(50 \mathrm{~mL})$ and $\mathrm{H}_{2} \mathrm{O}(50 \mathrm{~mL})$. After extraction, the organic phase was washed with brine $(50 \mathrm{~mL})$, dried $\left(\mathrm{MgSO}_{4}\right)$, filtered, and concentrated. The residue was dissolved in THF $(30 \mathrm{~mL})$ at $0{ }^{\circ} \mathrm{C}$ and a $1 \mathrm{M}$ solution of $\mathrm{Bu}_{4} \mathrm{~N}^{+} \mathrm{F}^{-}$in THF $(2$ equiv) was added. After stirring for $2 \mathrm{~h}$, the reaction mixture was diluted with $\mathrm{CH}_{2} \mathrm{Cl}_{2}(30 \mathrm{~mL})$ and the $\mathrm{CH}_{2} \mathrm{Cl}_{2}$ was washed with $\mathrm{H}_{2} \mathrm{O}$ $(30 \mathrm{~mL})$. The organic phase was dried $\left(\mathrm{MgSO}_{4}\right)$, filtered, and concentrated; the residue was purified by FC ( $n$-hexane-EtOAc, 98:2) to give $3 \mathbf{a}(1.83 \mathrm{~g}, 65 \%)$ as a foam.

${ }^{1} \mathrm{H} \mathrm{NMR}\left(300 \mathrm{MHz}, \mathrm{CDCl}_{3}\right): \delta=8.76$ (br s, $\left.1 \mathrm{H}\right), 8.44$ (br s, $1 \mathrm{H}$ ), $8.20(\mathrm{~d}, J=8.8 \mathrm{~Hz}, 1 \mathrm{H}), 7.65(\mathrm{~d}, J=1.9 \mathrm{~Hz}, 1 \mathrm{H}), 7.59-7.51(\mathrm{~m}, 2$ $\mathrm{H}), 7.36(\mathrm{~d}, J=1.4 \mathrm{~Hz}, 1 \mathrm{H}), 7.17(\mathrm{dd}, J=8.8,1.4 \mathrm{~Hz}, 1 \mathrm{H}), 2.35(\mathrm{~s}$, $3 \mathrm{H})$.

HRMS (EI): $\mathrm{m} / z$ calcd for $\mathrm{C}_{14} \mathrm{H}_{11} \mathrm{ClN}_{2}$ : 242.0611; found: 242.0622 .

Anal. Calcd for $\mathrm{C}_{14} \mathrm{H}_{11} \mathrm{ClN}_{2}$ : C, 69.28; $\mathrm{H}, 4.57 ; \mathrm{N}, 11.54 ; \mathrm{Cl}, 14.61$. Found: C, 69.33; H, 4.47; N, 11.61; Cl, 14.64.

\section{6-(6-Chloro-1H-indol-3-yl)quinoline (3b)}

Compound $\mathbf{3 b}$ ( $69 \%$ yield, foam) was prepared starting from $\mathbf{2 a}$ and from the proper heteroaryl bromide, according to the procedure described for 3a and purified by FC ( $n$-hexane-EtOAc, 98:2).

${ }^{1} \mathrm{H}$ NMR (400 MHz, DMSO- $\left.d_{6}\right): \delta=12.20(\mathrm{~s}, 1 \mathrm{H}), 8.89(\mathrm{dd}$, $J=5.2,1.5 \mathrm{~Hz}, 1 \mathrm{H}), 8.33(\mathrm{dd}, J=7.8,1.5 \mathrm{~Hz}, 1 \mathrm{H}), 8.04(\mathrm{br} \mathrm{d}$, $J=8.7 \mathrm{~Hz}, 1 \mathrm{H}), 8.00($ br s, $1 \mathrm{H}), 7.99(\mathrm{dd}, J=8.7,1.9 \mathrm{~Hz}, 1 \mathrm{H})$, $7.59(\mathrm{~d}, J=1.6 \mathrm{~Hz}, 1 \mathrm{H}), 7.57(\mathrm{dd}, J=7.8,5.2 \mathrm{~Hz}, 1 \mathrm{H}), 8.22(\mathrm{~d}$, $J=7.5 \mathrm{~Hz}, 1 \mathrm{H}$ ), 7.19 (dd, $J=7.5,1.4 \mathrm{~Hz}, 1 \mathrm{H}), 7.39$ (br s, $1 \mathrm{H}$ ).

HRMS (EI): $\mathrm{m} / z$ calcd for $\mathrm{C}_{17} \mathrm{H}_{11} \mathrm{ClN}_{2}$ : 278.0611; found: 278.0622 .

Anal. Calcd for $\mathrm{C}_{17} \mathrm{H}_{11} \mathrm{ClN}_{2}$ : C, 73.25; H, 3.98; N, 10.05; Cl, 12.72 . Found: C, 73.28; H, 3.88; N, 9.94; Cl, 12.69 .

\section{6-Chloro-3-[4-(furan-2-yl)phenyl]-1H-indole (3c)}

Compound 3c (87\% yield, foam) was prepared starting from 2a and from the proper heteroaryl bromide, according to the procedure described for 3a and purified by FC (cyclohexane).

${ }^{1} \mathrm{H}$ NMR (400 MHz, DMSO- $\left.d_{6}\right): \delta=11.6(\mathrm{~s}, 1 \mathrm{H}), 7.89$ (d, $J=8.5$ $\mathrm{Hz}, 1 \mathrm{H}), 7.79(\mathrm{~d}, J=2.2 \mathrm{~Hz}, 1 \mathrm{H}), 7.76-7.71(\mathrm{~m}, 5 \mathrm{H}), 7.53$ (br d, $J=1.3 \mathrm{~Hz}, 1 \mathrm{H}), 7.12(\mathrm{dd}, J=8.5,1.3 \mathrm{~Hz}, 1 \mathrm{H}), 6.91(\mathrm{~d}, J=3.5 \mathrm{~Hz}$, $1 \mathrm{H}), 6.61-6.59$ (m, $1 \mathrm{H})$.

HRMS (EI): $m / z$ calcd for $\mathrm{C}_{18} \mathrm{H}_{12} \mathrm{ClNO}$ : 293.0607; found: 293.0616.

Anal. Calcd for $\mathrm{C}_{18} \mathrm{H}_{12}$ ClNO: C, 73.60; H, 4.12; N, 4.77; Cl, 12.07 . Found: C, 73.67; H, 4.01; N, 4.67; Cl, 12.09 .

\section{6-Chloro-3-(6,7,8,9-tetrahydrodibenzo $[b, d]$ furan-2-yl)- $1 H$-in-} dole (3d)

Compound 3d (67\% yield, foam) was prepared starting from 2a and from the proper heteroaryl bromide, according to the procedure described for 3a and purified by FC ( $n$-hexane-EtOAc, 98:2).

${ }^{1} \mathrm{H}$ NMR (400 MHz, DMSO- $d_{6}$ ): $\delta=11.40$ (br s, $1 \mathrm{H}$ ), 7.85 (d, $J=8.5 \mathrm{~Hz}, 1 \mathrm{H}), 7.67(\mathrm{~s}, 1 \mathrm{H}), 7.66(\mathrm{~s}, 1 \mathrm{H}), 7.51$ (br s, $1 \mathrm{H}), 7.51-$ $7.47(\mathrm{~m}, 2 \mathrm{H}), 7.10(\mathrm{dd}, J=8.5,1.9 \mathrm{~Hz}, 1 \mathrm{H}), 2.75(\mathrm{br} \mathrm{t}, J=5.8 \mathrm{~Hz}$, $2 \mathrm{H}), 2.65$ (br t, $J=5.8 \mathrm{~Hz}, 2 \mathrm{H}), 1.94-1.89$ (m, $2 \mathrm{H}), 1.86-1.79$ (m, $2 \mathrm{H})$.

HRMS (EI): $\mathrm{m} / z$ calcd for $\mathrm{C}_{20} \mathrm{H}_{16} \mathrm{ClNO}$ : 321.0920; found: 321.0931.

Anal. Calcd for $\mathrm{C}_{20} \mathrm{H}_{16}$ CINO: C, 74.65; H, 5.01; N, 4.35; Cl, 11.02. Found: C, 74.71; H, 5.09; N, 4.25; Cl, 11.09 .

\section{3-(Benzofuran-5-yl)-6-chloro-1H-indole (3e)}

Compound 3e (79\% yield, foam) was prepared starting from $2 \mathbf{a}$ and from the proper heteroaryl bromide, according to the procedure described for 3a and purified by FC ( $n$-hexane-EtOAc, 98:2).

${ }^{1} \mathrm{H}$ NMR (400 MHz, DMSO- $\left.d_{6}\right): \delta=11.40($ br s, $1 \mathrm{H}), 7.99(\mathrm{~d}$, $J=2.0 \mathrm{~Hz}, 1 \mathrm{H}), 7.91(\mathrm{~d}, J=1.3 \mathrm{~Hz}, 1 \mathrm{H}), 7.87(\mathrm{~d}, J=8.3 \mathrm{~Hz}, 1 \mathrm{H})$, $7.70(\mathrm{~d}, J=2.3 \mathrm{~Hz}, 1 \mathrm{H}), 7.65(\mathrm{~d}, J=8.2 \mathrm{~Hz}, 1 \mathrm{H}), 7.59(\mathrm{dd}, J=8.3$, $1.3 \mathrm{~Hz}, 1 \mathrm{H}), 7.50(\mathrm{~d}, J=1.8 \mathrm{~Hz}, 1 \mathrm{H}), 7.11(\mathrm{dd}, J=8.3,1.8 \mathrm{~Hz}, 1$ $\mathrm{H}), 6.99(\mathrm{dd}, J=2.0,0.7 \mathrm{~Hz}, 1 \mathrm{H})$.

HRMS (EI): $\mathrm{m} / \mathrm{z}$ calcd for $\mathrm{C}_{16} \mathrm{H}_{10} \mathrm{ClNO}$ : 267.0451; found: 267.0444 .

Anal. Calcd for $\mathrm{C}_{16} \mathrm{H}_{10}$ CINO: C, 71.78; H, 3.77; N, 5.23; Cl, 13.24 . Found: C, 71.68; H, 3.65; N, 5.31; Cl, 13.28.

4,6-Dichloro-3-[5-(trifluoromethyl)pyridin-2-yl]- $1 H$-indole (3f) Compound $\mathbf{3 f}$ ( $95 \%$ yield, foam) was prepared starting from $\mathbf{2 b}$ and from the proper heteroaryl bromide, according to the procedure described for 3a and purified by FC ( $n$-hexane-EtOAc, 9:1).

${ }^{1} \mathrm{H} \mathrm{NMR}\left(300 \mathrm{MHz}, \mathrm{CDCl}_{3}\right): \delta=8.85$ (br s, $\left.1 \mathrm{H}\right), 8.72(\mathrm{br} \mathrm{s}, 1 \mathrm{H})$, 8.01 (br d, $J=7.5 \mathrm{~Hz}, 1 \mathrm{H}), 7.71(\mathrm{~d}, J=7.5 \mathrm{~Hz}, 1 \mathrm{H}), 7.39$ (br s, 1 $\mathrm{H}), 7.29(\mathrm{~d}, J=2.1 \mathrm{~Hz}, 1 \mathrm{H}), 7.19$ (br s, $1 \mathrm{H}$ ).

HRMS (EI): $\mathrm{m} / \mathrm{z}$ calcd for $\mathrm{C}_{14} \mathrm{H}_{7} \mathrm{Cl}_{2} \mathrm{~F}_{3} \mathrm{~N}_{2}$ : 329.9938; found: 329.9951.

Anal. Calcd for $\mathrm{C}_{14} \mathrm{H}_{7} \mathrm{Cl}_{2} \mathrm{~F}_{3} \mathrm{~N}_{2}$ : C, 50.78; H, 2.13; N, 8.46; Cl, 21.41 . Found: C, 50.61; H, 2.15; N, 8.52; Cl, 21.49 .

\section{6-(4,6-Dichloro-1H-indol-3-yl)quinoline (3g)}

Compound $\mathbf{3 g}$ ( $72 \%$ yield, foam) was prepared starting from $\mathbf{2 b}$ and from the proper heteroaryl bromide, according to the procedure described for 3a and purified by FC ( $n$-hexane-EtOAc, 98:2).

${ }^{1} \mathrm{H}$ NMR $\left(300 \mathrm{MHz}\right.$, DMSO- $\left.d_{6}\right): \delta=11.87$ (br s, $\left.1 \mathrm{H}\right), 8.90(\mathrm{dd}$, $J=4.1,1.9 \mathrm{~Hz}, 1 \mathrm{H}), 8.37(\mathrm{dd}, J=8.2,1.6 \mathrm{~Hz}, 1 \mathrm{H}), 8.02(\mathrm{~d}, J=7.5$ $\mathrm{Hz}, 1 \mathrm{H}), 8.01(\mathrm{~s}, 1 \mathrm{H}), 7.89$ (dd, $J=7.5,1.9 \mathrm{~Hz}, 1 \mathrm{H}), 7.67$ (d, $J=1.9 \mathrm{~Hz}, 1 \mathrm{H}), 7.56(\mathrm{~d}, J=1.6 \mathrm{~Hz}, 1 \mathrm{H}), 7.55(\mathrm{dd}, J=8.2,5.2 \mathrm{~Hz}$, $1 \mathrm{H}), 7.17(\mathrm{~d}, J=1.6 \mathrm{~Hz}, 1 \mathrm{H})$.

HRMS (EI): $\mathrm{m} / z$ calcd for $\mathrm{C}_{17} \mathrm{H}_{10} \mathrm{Cl}_{2} \mathrm{~N}_{2}$ : 312.0221; found: 312.0226.

Anal. Calcd for $\mathrm{C}_{17} \mathrm{H}_{10} \mathrm{Cl}_{2} \mathrm{~N}_{2}$ : C, 65.20; H, 3.22; N, 8.94; Cl, 22.64 . Found: C, 65.28; H, 3.31; N, 8.83; Cl, 22.54 .

\section{3-(4,6-Dichloro-1H-indol-3-yl)quinoline (3h)}

Compound $\mathbf{3 h}$ ( $96 \%$ yield, foam) was prepared starting from $\mathbf{2 b}$ and from the proper heteroaryl bromide, according to the procedure described for 3a and purified by FC ( $n$-hexane-EtOAc, 98:2).

${ }^{1} \mathrm{H}$ NMR $\left(300 \mathrm{MHz}, \mathrm{DMSO}-d_{6}\right)$ : $\delta=12.01(\mathrm{br} \mathrm{s}, 1 \mathrm{H}), 9.19$ (d, $J=1.6 \mathrm{~Hz}, 1 \mathrm{H}), 8.40$ (br s, $1 \mathrm{H}), 8.09(\mathrm{~d}, J=8.1 \mathrm{~Hz}, 1 \mathrm{H}), 8.03$ (d, 
$J=8.1 \mathrm{~Hz}, 1 \mathrm{H}), 7.80(\mathrm{~m}, 2 \mathrm{H}), 7.64(\mathrm{t}, J=8.1 \mathrm{~Hz}, 1 \mathrm{H}), 7.58(\mathrm{~d}$, $J=1.4 \mathrm{~Hz}, 1 \mathrm{H}), 7.25($ br s, $1 \mathrm{H})$.

HRMS (EI): $m / z$ calcd for $\mathrm{C}_{17} \mathrm{H}_{10} \mathrm{Cl}_{2} \mathrm{~N}_{2}: 312.0221$; found: 312.0218 .

Anal. Calcd for $\mathrm{C}_{17} \mathrm{H}_{10} \mathrm{Cl}_{2} \mathrm{~N}_{2}$ : C, 65.20; H, 3.22; N, 8.94; Cl, 22.64 . Found: C, 65.18; H, 3.26; N, 8.88; Cl, 22.55 .

6-(4,6-Dichloro- $1 H$-indol-3-yl)quinoxaline (3i)

Compound $\mathbf{3 i}$ (50\% yield, foam) was prepared starting from $\mathbf{2 b}$ and from the proper heteroaryl bromide, according to the procedure described for 3a and purified by FC ( $n$-hexane-EtOAc, 98:2).

${ }^{1} \mathrm{H}$ NMR $\left(300 \mathrm{MHz}, \mathrm{DMSO}-d_{6}\right): \delta=12.01(\mathrm{~s}, 1 \mathrm{H}), 9.00-8.94(\mathrm{~m}$, $2 \mathrm{H}), 8.13(\mathrm{~d}, J=2.9 \mathrm{~Hz}, 1 \mathrm{H}), 8.13(\mathrm{~d}, J=8.0 \mathrm{~Hz}, 1 \mathrm{H}), 8.02(\mathrm{dd}$, $J=8.0,2.9 \mathrm{~Hz}, 1 \mathrm{H}), 7.80(\mathrm{~s}, 1 \mathrm{H}), 7.58(\mathrm{~d}, J=1.8 \mathrm{~Hz}, 1 \mathrm{H}), 7.24$ (d, $J=1.8 \mathrm{~Hz}, 1 \mathrm{H})$.

HRMS (EI): $\mathrm{m} / z$ calcd for $\mathrm{C}_{16} \mathrm{H}_{9} \mathrm{Cl}_{2} \mathrm{~N}_{3}: 313.0174$; found: 313.0153 . Anal. Calcd for $\mathrm{C}_{16} \mathrm{H}_{9} \mathrm{Cl}_{2} \mathrm{~N}_{3}: \mathrm{C}, 61.17 ; \mathrm{H}, 2.89 ; \mathrm{N}, 13.38 ; \mathrm{Cl}, 22.57$. Found: C, 61.08; H, 2.95; N, 13.27; Cl, 22.50.

1-[5-(4,6-Dichloro-1 $\mathrm{H}$-indol-3-yl)benzofuran-2-yl]ethanone (3j) Compound $\mathbf{3 j}$ (63\% yield, foam) was prepared starting from $\mathbf{2 b}$ and from the proper heteroaryl bromide, according to the procedure described for 3a and purified by FC ( $n$-hexane-EtOAc, 98:2).

${ }^{1} \mathrm{H}$ NMR (400 MHz, DMSO- $\left.d_{6}\right): \delta=11.76(\mathrm{~s}, 1 \mathrm{H}), 7.91(\mathrm{br} \mathrm{s}, 1 \mathrm{H})$, 7.85 (br d, $J=1.3 \mathrm{~Hz}, 1 \mathrm{H}), 7.71(\mathrm{br} \mathrm{d}, J=8.5 \mathrm{~Hz}, 1 \mathrm{H}), 7.61$ (dd, $J=8.5,1.9 \mathrm{~Hz}, 1 \mathrm{H}), 7.56(\mathrm{~s}, 1 \mathrm{H}), 7.53(\mathrm{~d}, J=1.9 \mathrm{~Hz}, 1 \mathrm{H}), 7.14$ $(\mathrm{d}, J=1.9 \mathrm{~Hz}, 1 \mathrm{H}), 2.59$ (s, $3 \mathrm{H})$.

HRMS (EI): $\mathrm{m} / \mathrm{z}$ calcd for $\mathrm{C}_{18} \mathrm{H}_{11} \mathrm{Cl}_{2} \mathrm{NO}_{2}$ : 343.0167; found: 343.0176.

Anal. Calcd for $\mathrm{C}_{18} \mathrm{H}_{11} \mathrm{Cl}_{2} \mathrm{NO}_{2}$ : C, 62.81; H, 3.22; N, 4.07; Cl, 20.60. Found: C, 62.99; H, 3.31; N, 4.00; Cl, 20.55.

\section{Preparation of $t$-BuOCI}

In a flask containing commercial bleach $(50 \mathrm{~mL})$ cooled at $10^{\circ} \mathrm{C}$ were quickly added $t$-BuOH $(74.1 \mathrm{~g} / \mathrm{mol}, 3.7 \mathrm{~mL}, 39 \mathrm{mmol}, 0.79 \mathrm{~g} /$ $\mathrm{mL}, 1$ equiv) and glacial AcOH $(60.0 \mathrm{~g} / \mathrm{mol}, 2.45 \mathrm{~mL}, 43 \mathrm{mmol}$, $1.05 \mathrm{~g} / \mathrm{mL}, 1.1$ equiv). This mixture was stirred for $5 \mathrm{~min}$, then the organic layer was separated and washed with $10 \%$ aq $\mathrm{NaHCO}_{3}(5$ $\mathrm{mL}$ ) and then with $\mathrm{H}_{2} \mathrm{O}(5 \mathrm{~mL})$. The organic phase (yellow oil, $t$ $\mathrm{BuOCl}, 3 \mathrm{~g}$ ) was dried with $\mathrm{CaCl}_{2}$ and conserved in freezer. CAUTION: avoid exposure to light and contact with plastic material and metallic needles.

\section{Oxidation of 3-Heteroarylindoles 3 with $t$-BuOCl; \\ General Procedure}

To a solution of $t$ - $\mathrm{BuOCl}(108.4 \mathrm{~g} / \mathrm{mol}, 0.24 \mathrm{~mL}, 2.0 \mathrm{mmol}, 2.0$ equiv, $0.91 \mathrm{~g} / \mathrm{mL})$ in anhyd $\mathrm{CH}_{2} \mathrm{Cl}_{2}(3 \mathrm{~mL})$ was added a solution of indole $3(1.0 \mathrm{mmol})$ in anhyd $\mathrm{CH}_{2} \mathrm{Cl}_{2}(3 \mathrm{~mL})$ and the reaction mixture was stirred at r.t. for $1 \mathrm{~h}$. Then, the solvent was evaporated under a $\mathrm{N}_{2}$ stream and the residue was treated with $3 \mathrm{~N}$ aq 1,4dioxane- $\mathrm{H}_{2} \mathrm{SO}_{4}(2: 1,3 \mathrm{~mL})$ and stirred for $1 \mathrm{~h}$. Sat. aq $\mathrm{NaHCO}_{3}(10$ $\mathrm{mL})$ was added and the mixture was extracted with $\mathrm{CH}_{2} \mathrm{Cl}_{2}(2 \times 2$ $\mathrm{mL})$. The combined organic layers were dried $\left(\mathrm{Na}_{2} \mathrm{SO}_{4}\right)$, filtered, and evaporated to dryness. The residue was purified by FC on silica gel (see below) to give the products as foams.

\section{2,6-Dichloro-3-(5-methylpyridin-2-yl)- $1 \mathrm{H}$-indole (4a)}

FC (hexane-EtOAc, 1:1).

${ }^{1} \mathrm{H}$ NMR (300 MHz, $\mathrm{CDCl}_{3}$ ): $\delta=8.81$ (br s, $\left.1 \mathrm{H}\right), 8.56$ (br s, $\left.1 \mathrm{H}\right)$, $8.02(\mathrm{~d}, J=8.9 \mathrm{~Hz}, 1 \mathrm{H}), 7.66-7.63(\mathrm{~m}, 1 \mathrm{H}), 7.58-7.55(\mathrm{~m}, 1 \mathrm{H})$, 7.19 (br s, $1 \mathrm{H}), 7.11$ (dd, $J=8.9,2.3 \mathrm{~Hz}, 1 \mathrm{H}), 2.32$ (s, $3 \mathrm{H})$.

HRMS (EI): $m / z$ calcd for $\mathrm{C}_{14} \mathrm{H}_{10} \mathrm{Cl}_{2} \mathrm{~N}_{2}:$ 276.0221; found: 276.0231 .
Anal. Calcd for $\mathrm{C}_{14} \mathrm{H}_{10} \mathrm{Cl}_{2} \mathrm{~N}_{2}$ : C, 60.67; H, 3.64; N, 10.11; Cl, 25.58 . Found: C, 60.58; H, 3.54; N, 10.26; Cl, 25.52.

\section{3,6-Dichloro-3-(5-methylpyridin-2-yl)indolin-2-one (6a)}

FC (hexane-EtOAc, 1:1)

${ }^{1} \mathrm{H}$ NMR $\left(300 \mathrm{MHz}, \mathrm{CDCl}_{3}\right.$ ): $\delta=8.78$ (br s, $\left.1 \mathrm{H}\right), 8.32$ (d, $J=1.1$ $\mathrm{Hz}, 1 \mathrm{H}), 7.87(\mathrm{~d}, J=9.8 \mathrm{~Hz}, 1 \mathrm{H}), 7.58(\mathrm{dd}, J=9.8,1.1 \mathrm{~Hz}, 1 \mathrm{H})$, $7.21(\mathrm{~d}, J=8.9 \mathrm{~Hz}, 1 \mathrm{H}), 7.01(\mathrm{dd}, J=8.9,2.8 \mathrm{~Hz}, 1 \mathrm{H}), 6.89(\mathrm{~d}$, $J=2.8 \mathrm{~Hz}, 1 \mathrm{H}), 2.33(\mathrm{~s}, 3 \mathrm{H})$.

HRMS (EI): $\mathrm{m} / z$ calcd for $\mathrm{C}_{14} \mathrm{H}_{10} \mathrm{Cl}_{2} \mathrm{~N}_{2} \mathrm{O}$ : 292.0170; found: 292.0155 .

Anal. Calcd for $\mathrm{C}_{14} \mathrm{H}_{10} \mathrm{Cl}_{2} \mathrm{~N}_{2} \mathrm{O}: \mathrm{C}, 57.36 ; \mathrm{H}, 3.44 ; \mathrm{N}, 9.56 ; \mathrm{Cl}$, 24.19. Found: C, 57.39; H, 3.34; N, 9.65; Cl, 24.16.

\section{3,6-Dichloro-3-(quinolin-6-yl)indolin-2-one (6b)}

FC (hexane-EtOAc, 8:2).

${ }^{1} \mathrm{H}$ NMR (300 MHz, DMSO- $\left.d_{6}\right): \delta=10.80$ (s, $1 \mathrm{H}$ ), 8.90 (dd, $J=4.0,1.9 \mathrm{~Hz}, 1 \mathrm{H}), 8.35(\mathrm{~d}, J=8.5 \mathrm{~Hz}, 1 \mathrm{H}), 7.93(\mathrm{~d}, J=8.7 \mathrm{~Hz}$, $1 \mathrm{H}), 7.77(\mathrm{~d}, J=1.7 \mathrm{~Hz}, 1 \mathrm{H}), 7.55(\mathrm{dd}, J=8.5,4.0 \mathrm{~Hz}, 1 \mathrm{H}), 7.42$ $(\mathrm{dd}, J=8.7,1.8 \mathrm{~Hz}, 1 \mathrm{H}), 7.23(\mathrm{~d}, J=1.7 \mathrm{~Hz}, 1 \mathrm{H}), 7.13-7.00(\mathrm{~m}$, $2 \mathrm{H})$.

HRMS (EI): $m / z$ calcd for $\mathrm{C}_{17} \mathrm{H}_{10} \mathrm{Cl}_{2} \mathrm{~N}_{2} \mathrm{O}$ : 328.0170; found: 328.0187.

Anal. Calcd for $\mathrm{C}_{17} \mathrm{H}_{10} \mathrm{Cl}_{2} \mathrm{~N}_{2} \mathrm{O}: \mathrm{C}, 62.03 ; \mathrm{H}, 3.06 ; \mathrm{N}, 8.51 ; \mathrm{Cl}$, 21.54. Found: C, 62.23; H, 3.15; N, 8.47; Cl, 21.45.

\section{3,6-Dichloro-3-[4-(furan-2-yl)phenyl]indolin-2-one (6c)}

FC (hexane-EtOAc, 9:1)

${ }^{1} \mathrm{H}$ NMR (400 MHz, DMSO- $\left.d_{6}\right): \delta=11.14(\mathrm{br} \mathrm{s}, 1 \mathrm{H}), 7.86(\mathrm{~d}$, $J=2.0 \mathrm{~Hz}, 1 \mathrm{H}), 7.72-7.70(\mathrm{~m}, 2 \mathrm{H}), 7.53-7.51(\mathrm{~m}, 3 \mathrm{H}), 7.44(\mathrm{~d}$, $J=8.2 \mathrm{~Hz}, 1 \mathrm{H}), 7.18(\mathrm{dd}, J=8.2,1.9 \mathrm{~Hz}, 1 \mathrm{H}), 7.04(\mathrm{~d}, J=3.5 \mathrm{~Hz}$, $1 \mathrm{H}), 6.62-6.64(\mathrm{~m}, 1 \mathrm{H})$.

HRMS (EI): $m / z$ calcd for $\mathrm{C}_{18} \mathrm{H}_{11} \mathrm{Cl}_{2} \mathrm{NO}_{2}$ : 343.0167; found: 343.0176.

Anal. Calcd for $\mathrm{C}_{18} \mathrm{H}_{11} \mathrm{Cl}_{2} \mathrm{NO}_{2}: \mathrm{C}, 62.81 ; \mathrm{H}, 3.22 ; \mathrm{N}, 4.07 ; \mathrm{Cl}$, 20.60. Found: C, 62.88; H, 3.26; N, 4.00; Cl, 20.62.

\section{3,6-Dichloro-3-(6,7,8,9-tetrahydrodibenzo[b,d]furan-2-yl)indo-} lin-2-one (6d)

FC (hexane-EtOAc, 95:5).

${ }^{1} \mathrm{H}$ NMR $\left(400 \mathrm{MHz}\right.$, DMSO- $\left.d_{6}\right): \delta=10.50(\mathrm{~s}, 1 \mathrm{H}), 7.45(\mathrm{~d}, J=1.8$ $\mathrm{Hz}, 1 \mathrm{H}), 7.37$ (d, $J=8.6 \mathrm{~Hz}, 1 \mathrm{H}), 7.12-7.10(\mathrm{~m}, 1 \mathrm{H}), 7.05-6.99$ $(\mathrm{m}, 2 \mathrm{H}), 6.93(\mathrm{~d}, J=1.7 \mathrm{~Hz}, 1 \mathrm{H}), 2.73-2.70(\mathrm{~m}, 2 \mathrm{H}), 2.57-2.54$ (m, 2 H), 1.90-1.87 (m, 2 H), 1.81-1.78 (m, 2 H).

HRMS (EI): $\mathrm{m} / \mathrm{z}$ calcd for $\mathrm{C}_{20} \mathrm{H}_{15} \mathrm{Cl}_{2} \mathrm{NO}_{2}: 371.0480$; found: 371.0489 .

Anal. Calcd for $\mathrm{C}_{20} \mathrm{H}_{15} \mathrm{Cl}_{2} \mathrm{NO}_{2}$ : C, 64.53; H, 4.06; N, 3.76; $\mathrm{Cl}$, 19.05. Found: C, 64.64; H, 4.12; N, 3.66; Cl, 19.10 .

\section{3-(Benzofuran-5-yl)-3,6-dichloroindolin-2-one (6e)}

FC (hexane-EtOAc, 97:3).

${ }^{1} \mathrm{H}$ NMR (400 MHz, DMSO- $\left.d_{6}\right): \delta=10.50(\mathrm{~s}, 1 \mathrm{H}), 7.96$ (d, $J=2.2$ $\mathrm{Hz}, 1 \mathrm{H}), 7.58(\mathrm{~d}, J=1.8 \mathrm{~Hz}, 1 \mathrm{H}), 7.52(\mathrm{~d}, J=8.6 \mathrm{~Hz}, 1 \mathrm{H}), 7.23$ $(\mathrm{dd}, J=8.7,1.9 \mathrm{~Hz}, 1 \mathrm{H}), 7.14(\mathrm{~d}, J=8.1 \mathrm{~Hz}, 1 \mathrm{H}), 7.04-7.02(\mathrm{~m}$, $1 \mathrm{H}), 6.96-6.94$ (m, $2 \mathrm{H})$.

HRMS (EI): $m / z$ calcd for $\mathrm{C}_{16} \mathrm{H}_{9} \mathrm{Cl}_{2} \mathrm{NO}_{2}: 317.0010$; found: 317.0019 .

Anal. Calcd for $\mathrm{C}_{16} \mathrm{H}_{9} \mathrm{Cl}_{2} \mathrm{NO}_{2}$ : C, 60.40; $\mathrm{H}, 2.85 ; \mathrm{N}, 4.40 ; \mathrm{Cl}, 22.29$. Found: C, 60.30; H, 2.79; N, 4.35; Cl, 22.22. 
2,4,6-Trichloro-3-[5-(trifluoromethyl)pyridin-2-yl]- $1 H$-indole (4f)

FC (hexane-EtOAc, 9:1).

${ }^{1} \mathrm{H}$ NMR $\left(300 \mathrm{MHz}, \mathrm{CDCl}_{3}\right): \delta=9.09(\mathrm{br} \mathrm{s}, 1 \mathrm{H}), 8.82(\mathrm{~d}, J=1.4$ $\mathrm{Hz}, 1 \mathrm{H}), 7.97$ (dd, $J=8.2,1.4 \mathrm{~Hz}, 1 \mathrm{H}), 7.77(\mathrm{~d}, J=8.2 \mathrm{~Hz}, 1 \mathrm{H})$, $7.32(\mathrm{~d}, J=2.8 \mathrm{~Hz}, 1 \mathrm{H}), 7.17(\mathrm{~d}, J=2.8 \mathrm{~Hz}, 1 \mathrm{H})$.

HRMS (EI): $m / z$ calcd for $\mathrm{C}_{14} \mathrm{H}_{6} \mathrm{Cl}_{3} \mathrm{~F}_{3} \mathrm{~N}_{2}: 363.9549$; found: 363.9557.

Anal. Calcd for $\mathrm{C}_{14} \mathrm{H}_{6} \mathrm{Cl}_{3} \mathrm{~F}_{3} \mathrm{~N}_{2}$ : C, 46.00; H, 1.65; N, 7.66; Cl, 29.09. Found: C, 45.88; H, 1.54; N, 7.75; Cl, 29.01.

\section{4,6-Dichloro-3-[5-(trifluoromethyl)pyridin-2-yl]indolin-2-one (5f)}

FC (hexane-EtOAc, 9:1).

${ }^{1} \mathrm{H} \mathrm{NMR}\left(300 \mathrm{MHz}, \mathrm{CDCl}_{3}\right): \delta=8.62(\mathrm{~s}, 1 \mathrm{H}), 8.48(\mathrm{br} \mathrm{s}, 1 \mathrm{H}), 7.64$ (s, $2 \mathrm{H}), 7.09(\mathrm{~d}, J=1.3 \mathrm{~Hz}, 1 \mathrm{H}), 6.92(\mathrm{~d}, J=1.3 \mathrm{~Hz}, 1 \mathrm{H}), 4.68$ (s, $1 \mathrm{H})$.

HRMS (EI): $m / z$ calcd for $\mathrm{C}_{14} \mathrm{H}_{7} \mathrm{Cl}_{2} \mathrm{~F}_{3} \mathrm{~N}_{2} \mathrm{O}$ : 345.9888; found: 345.9903.

Anal. Calcd for $\mathrm{C}_{14} \mathrm{H}_{7} \mathrm{Cl}_{2} \mathrm{~F}_{3} \mathrm{~N}_{2} \mathrm{O}$ : C, 48.44; $\mathrm{H}, 2.03 ; \mathrm{N}, 8.07 ; \mathrm{Cl}$, 20.43. Found: C, 48.52; H, 2.11; N, 8.01; Cl, 20.39.

\section{3,4,6-Trichloro-3-[5-(trifluoromethyl)pyridin-2-yl]indolin-2- one (6f) \\ FC (hexane-EtOAc, 9:1).}

${ }^{1} \mathrm{H} \mathrm{NMR}\left(300 \mathrm{MHz}, \mathrm{CDCl}_{3}\right): \delta=8.66$ (br s, $\left.1 \mathrm{H}\right), 8.33$ (br s, $\left.1 \mathrm{H}\right)$, $8.13(\mathrm{dd}, J=8.9,1.3 \mathrm{~Hz}, 1 \mathrm{H}), 7.75(\mathrm{~d}, J=8.9 \mathrm{~Hz}, 1 \mathrm{H}), 7.17$ (s, 1 H), 6.97 (br s, $1 \mathrm{H}$ ).

HRMS (EI): $m / z$ calcd for $\mathrm{C}_{14} \mathrm{H}_{6} \mathrm{Cl}_{3} \mathrm{~F}_{3} \mathrm{~N}_{2} \mathrm{O}$ : 379.9498; found: 379.9507.

Anal. Calcd for $\mathrm{C}_{14} \mathrm{H}_{6} \mathrm{Cl}_{3} \mathrm{~F}_{3} \mathrm{~N}_{2} \mathrm{O}: \mathrm{C}, 44.07 ; \mathrm{H}, 1.58 ; \mathrm{N}, 7.34 ; \mathrm{Cl}$, 27.87. Found: C, 44.00; H, 1.71; N, 7.39; Cl, 27.81.

\section{4,6-Dichloro-3-(quinolin-6-yl)indolin-2-one (5g) \\ FC (hexane-EtOAc, 8:2).}

${ }^{1} \mathrm{H}$ NMR $\left(300 \mathrm{MHz}\right.$, DMSO- $\left.d_{6}\right): \delta=10.90(\mathrm{~s}, 1 \mathrm{H}), 8.90(\mathrm{dd}$, $J=4.1,1.9 \mathrm{~Hz}, 1 \mathrm{H}), 8.37(\mathrm{~d}, J=8.5 \mathrm{~Hz}, 1 \mathrm{H}), 7.98(\mathrm{~d}, J=8.8 \mathrm{~Hz}$, $1 \mathrm{H}), 7.78(\mathrm{~d}, J=1.8 \mathrm{~Hz}, 1 \mathrm{H}), 7.55(\mathrm{dd}, J=8.2,4.0 \mathrm{~Hz}, 1 \mathrm{H}), 7.46$ $(\mathrm{dd}, J=8.8,1.8 \mathrm{~Hz}, 1 \mathrm{H}), 7.16(\mathrm{~d}, J=1.7 \mathrm{~Hz}, 1 \mathrm{H}), 6.98(\mathrm{~d}, J=1.7$ $\mathrm{Hz}, 1 \mathrm{H}), 5.08$ (s, $1 \mathrm{H})$.

HRMS (EI): $m / z$ calcd for $\mathrm{C}_{17} \mathrm{H}_{10} \mathrm{Cl}_{2} \mathrm{~N}_{2} \mathrm{O}$ : 328.0170; found: 328.0175 .

Anal. Calcd for $\mathrm{C}_{17} \mathrm{H}_{10} \mathrm{Cl}_{2} \mathrm{~N}_{2} \mathrm{O}: \mathrm{C}, 62.03 ; \mathrm{H}, 3.06 ; \mathrm{N}, 8.51 ; \mathrm{Cl}$, 21.54. Found: C, 62.13; H, 3.09; N, 8.48; Cl, 21.50.

\section{3,4,6-Trichloro-3-(quinolin-6-yl)indolin-2-one (6g)} FC (hexane-EtOAc, 8:2).

${ }^{1} \mathrm{H}$ NMR (300 MHz, DMSO- $\left.d_{6}\right): \delta=10.87$ (s, $\left.1 \mathrm{H}\right), 8.88(\mathrm{dd}$, $J=4.1,1.8 \mathrm{~Hz}, 1 \mathrm{H}), 8.35(\mathrm{~d}, J=8.5 \mathrm{~Hz}, 1 \mathrm{H}), 7.95(\mathrm{~d}, J=8.8 \mathrm{~Hz}$, $1 \mathrm{H}), 7.76(\mathrm{~d}, J=1.8 \mathrm{~Hz}, 1 \mathrm{H}), 7.52(\mathrm{dd}, J=8.2,4.0 \mathrm{~Hz}, 1 \mathrm{H}), 7.44$ $(\mathrm{dd}, J=8.7,1.8 \mathrm{~Hz}, 1 \mathrm{H}), 7.23(\mathrm{~d}, J=1.7 \mathrm{~Hz}, 1 \mathrm{H}), 7.03(\mathrm{~d}, J=1.7$ $\mathrm{Hz}, 1 \mathrm{H})$.

HRMS (EI): $\mathrm{m} / \mathrm{z}$ calcd for $\mathrm{C}_{17} \mathrm{H}_{9} \mathrm{Cl}_{3} \mathrm{~N}_{2} \mathrm{O}:$ 361.9780; found: 361.9787.

Anal. Calcd for $\mathrm{C}_{17} \mathrm{H}_{9} \mathrm{Cl}_{3} \mathrm{~N}_{2} \mathrm{O}: \mathrm{C}, 56.15 ; \mathrm{H}, 2.49 ; \mathrm{N}, 7.70 ; \mathrm{Cl}, 29.25$. Found: C, 56.21; H, 2.57; N, 7.67; Cl, 29.23.

\section{4,6-Dichloro-3-(quinolin-3-yl)indolin-2-one (5h)}

FC (hexane-EtOAc, 9:1).

${ }^{1} \mathrm{H}$ NMR $\left(300 \mathrm{MHz}, \mathrm{DMSO}-d_{6}\right): \delta=11.12(\mathrm{~s}, 1 \mathrm{H}), 8.78(\mathrm{~d}, J=2.1$ $\mathrm{Hz}, 1 \mathrm{H}), 8.10$ (d, $J=1.4 \mathrm{~Hz}, 1 \mathrm{H}), 8.05(\mathrm{~d}, J=9.2 \mathrm{~Hz}, 1 \mathrm{H}), 8.01$ (d, $J=9.2 \mathrm{~Hz}, 1 \mathrm{H}), 7.78(\mathrm{t}, J=8.2 \mathrm{~Hz}, 1 \mathrm{H}), 7.63(\mathrm{t}, J=8.2 \mathrm{~Hz}, 1$ H), 7.23 (br s, $1 \mathrm{H}), 7.02$ (br s, $1 \mathrm{H}), 5.05$ (s, $1 \mathrm{H})$.

HRMS (EI): $\mathrm{m} / \mathrm{z}$ calcd for $\mathrm{C}_{17} \mathrm{H}_{10} \mathrm{Cl}_{2} \mathrm{~N}_{2} \mathrm{O}$ : 328.0170; found: 328.0179 .

Anal. Calcd for $\mathrm{C}_{17} \mathrm{H}_{10} \mathrm{Cl}_{2} \mathrm{~N}_{2} \mathrm{O}: \mathrm{C}, 62.03 ; \mathrm{H}, 3.06 ; \mathrm{N}, 8.51 ; \mathrm{Cl}$, 21.54. Found: C, 62.12; H, 3.17; N, 8.45; Cl, 21.50.

\section{3,4,6-Trichloro-3-(quinolin-3-yl)indolin-2-one (6h)}

FC (hexane-EtOAc, 9:1).

${ }^{1} \mathrm{H}$ NMR $\left(300 \mathrm{MHz}, \mathrm{DMSO}-d_{6}\right): \delta=11.58(\mathrm{~s}, 1 \mathrm{H}), 8.88(\mathrm{~d}, J=1.1$ $\mathrm{Hz}, 1 \mathrm{H}), 8.46(\mathrm{~d}, J=1.1 \mathrm{~Hz}, 1 \mathrm{H}), 8.14(\mathrm{~d}, J=8.9 \mathrm{~Hz}, 1 \mathrm{H}), 8.09$ $(\mathrm{d}, J=8.9 \mathrm{~Hz}, 1 \mathrm{H}), 7.86(\mathrm{t}, J=7.5 \mathrm{~Hz}, 1 \mathrm{H}), 7.7(\mathrm{t}, J=7.5 \mathrm{~Hz}, 1$ H), 7.44 (s, $1 \mathrm{H}), 7.15$ (s, $1 \mathrm{H})$.

HRMS (EI): $\mathrm{m} / z$ calcd for $\mathrm{C}_{17} \mathrm{H}_{9} \mathrm{Cl}_{3} \mathrm{~N}_{2} \mathrm{O}$ : 361.9780; found: 361.9787.

Anal. Calcd for $\mathrm{C}_{17} \mathrm{H}_{9} \mathrm{Cl}_{3} \mathrm{~N}_{2} \mathrm{O}: \mathrm{C}, 56.15 ; \mathrm{H}, 2.49 ; \mathrm{N}, 7.70 ; \mathrm{Cl}, 29.25$. Found: C, 56.23; H, 2.42; N, 7.60; Cl, 29.21.

\section{4,6-Dichloro-3-(quinoxalin-6-yl)indolin-2-one (5i)} FC (hexane-EtOAc, 9:1).

${ }^{1} \mathrm{H}$ NMR $\left(400 \mathrm{MHz}, \mathrm{DMSO}-d_{6}\right): \delta=11.08(\mathrm{~s}, 1 \mathrm{H}), 8.98$ (br s, $2 \mathrm{H}$ ), $8.08(\mathrm{~d}, J=8.5 \mathrm{~Hz}, 1 \mathrm{H}), 7.93(\mathrm{~d}, J=1.5 \mathrm{~Hz}, 1 \mathrm{H}), 7.54(\mathrm{dd}, J=8.6$, $1.5 \mathrm{~Hz}, 1 \mathrm{H}), 7.18(\mathrm{~d}, J=1.7 \mathrm{~Hz}, 1 \mathrm{H}), 7.02(\mathrm{~d}, J=1.7 \mathrm{~Hz}, 1 \mathrm{H})$, $5.23(\mathrm{~s}, 1 \mathrm{H})$.

HRMS (EI): $\mathrm{m} / \mathrm{z}$ calcd for $\mathrm{C}_{16} \mathrm{H}_{9} \mathrm{Cl}_{2} \mathrm{~N}_{3} \mathrm{O}:$ 329.0123; found: 329.0115.

Anal. Calcd for $\mathrm{C}_{16} \mathrm{H}_{9} \mathrm{Cl}_{2} \mathrm{~N}_{3} \mathrm{O}: \mathrm{C}, 58.20 ; \mathrm{H}, 2.75 ; \mathrm{N}, 12.73 ; \mathrm{Cl}$, 21.48. Found: C, 58.25; H, 2.68; N, 12.69; Cl, 21.58

\section{3,4,6-Trichloro-3-(quinoxalin-6-yl)indolin-2-one (6i)}

FC (hexane-EtOAc, 9:1).

${ }^{1} \mathrm{H}$ NMR (400 MHz, DMSO- $\left.d_{6}\right): \delta=10.97$ (s, $\left.1 \mathrm{H}\right), 9.11$ (br s, $2 \mathrm{H}$ ), $8,24(\mathrm{~d}, J=8.4 \mathrm{~Hz}, 1 \mathrm{H}), 7.95(\mathrm{~d}, J=1.6 \mathrm{~Hz}, 1 \mathrm{H}), 7.82(\mathrm{dd}, J=8.5$, $1.5 \mathrm{~Hz}, 1 \mathrm{H}), 7.43(\mathrm{~d}, J=1.6 \mathrm{~Hz}, 1 \mathrm{H}), 7.14(\mathrm{~d}, J=1.6 \mathrm{~Hz}, 1 \mathrm{H})$.

HRMS (EI): $\mathrm{m} / \mathrm{z}$ calcd for $\mathrm{C}_{16} \mathrm{H}_{8} \mathrm{Cl}_{3} \mathrm{~N}_{3} \mathrm{O}:$ 362.9733; found: 362.9726.

Anal. Calcd for $\mathrm{C}_{16} \mathrm{H}_{8} \mathrm{Cl}_{3} \mathrm{~N}_{3} \mathrm{O}: \mathrm{C}, 52.71 ; \mathrm{H}, 2.21 ; \mathrm{N}, 11.52 ; \mathrm{Cl}$, 29.17. Found: C, 52.80; H, 2.25; N, 11.48; Cl, 29.12.

\section{3-(2-Acetylbenzofuran-5-yl)-4,6-dichloroindolin-2-one (5j)}

FC (hexane-EtOAc, 8:2).

${ }^{1} \mathrm{H}$ NMR (400 MHz, DMSO- $\left.d_{6}\right): \delta=10.85(\mathrm{~s}, 1 \mathrm{H}), 7.84(\mathrm{~s}, 1 \mathrm{H})$, $7.67(\mathrm{~d}, J=8.8 \mathrm{~Hz}, 1 \mathrm{H}), 7.59(\mathrm{~d}, J=1.3 \mathrm{~Hz}, 1 \mathrm{H}), 7.26(\mathrm{dd}, J=8.6$, $1.7 \mathrm{~Hz}, 1 \mathrm{H}), 7.15(\mathrm{~d}, J=1.5 \mathrm{~Hz}, 1 \mathrm{H}), 6.97(\mathrm{~d}, J=1.5 \mathrm{~Hz}, 1 \mathrm{H}), 5.0$ (s, $1 \mathrm{H}), 2.56(\mathrm{~s}, 3 \mathrm{H})$.

HRMS (EI): $\mathrm{m} / \mathrm{z}$ calcd for $\mathrm{C}_{18} \mathrm{H}_{11} \mathrm{Cl}_{2} \mathrm{NO}_{3}$ : 359.0116; found: 359.0131 .

Anal. Calcd for $\mathrm{C}_{18} \mathrm{H}_{11} \mathrm{Cl}_{2} \mathrm{NO}_{3}: \mathrm{C}, 60.02 ; \mathrm{H}, 3.08 ; \mathrm{N}, 3.89 ; \mathrm{Cl}$, 19.69. Found: C, 60.12; H, 3.15; N, 3.82; Cl, 19.63.

\section{3-(2-Acetylbenzofuran-5-yl)-3,4,6-trichloroindolin-2-one (6j)} FC (hexane-EtOAc, 8:2).

${ }^{1} \mathrm{H}$ NMR (400 MHz, DMSO- $\left.d_{6}\right): \delta=11.38(\mathrm{~s}, 1 \mathrm{H}), 7.90(\mathrm{~m}, 2 \mathrm{H})$, $7.76(\mathrm{~d}, J=8.8 \mathrm{~Hz}, 1 \mathrm{H}), 7.51(\mathrm{dd}, J=8.8,2.0 \mathrm{~Hz}, 1 \mathrm{H}), 7.35(\mathrm{~d}$, $J=1.5 \mathrm{~Hz}, 1 \mathrm{H}), 7.08(\mathrm{~d}, J=1.5 \mathrm{~Hz}, 1 \mathrm{H}), 2.57$ (s, $3 \mathrm{H})$.

HRMS (EI): $\mathrm{m} / \mathrm{z}$ calcd for $\mathrm{C}_{18} \mathrm{H}_{10} \mathrm{Cl}_{3} \mathrm{NO}_{3}:$ 392.9726; found: 392.9732 .

Anal. Calcd for $\mathrm{C}_{18} \mathrm{H}_{10} \mathrm{Cl}_{3} \mathrm{NO}_{3}: \mathrm{C}, 54.78 ; \mathrm{H}, 2.55 ; \mathrm{N}, 3.55 ; \mathrm{Cl}$, 26.95. Found: C, 54.85; H, 2.60; N, 3.51; Cl, 26.94. 


\section{References}

(1) (a) Galliford, C. V.; Scheidt, K. A. Angew. Chem. Int. Ed. 2007, 46, 8748. (b) Marti, C.; Carreira, E. M. Eur. J. Org. Chem. 2003, 2209.

(2) (a) Kumar, R. R.; Perumal, S.; Senthilkumar, P.; Yogeeswari, P.; Dharmarajan, S. J. Med. Chem. 2008, 51, 5731. (b) Mendel, D. B.; Laird, A. D.; Xin, X. H.; Louie, S. G.; Christensen, J. G.; Li, G. M.; Schreck, R. E.; Abrams, T. J.; Ngai, T. J.; Lee, L. B.; Murray, L. J.; Carver, J.; Chan, E.; Moss, K. G.; Haznedar, J. O.; Sukbuntherng, J.; Blake, R. A.; Sun, L.; Tang, C.; Miller, T.; Shirazian, S.; McMahon, G.; Cherrington, J. M. Clin. Cancer Res. 2003, 9, 327. (c) Sun, L.; Liang, C.; Shirazian, S.; Zhou, Y.; Miller, T.; Cui, J.; Fukuda, J. Y.; Chu, J. Y.; Nematalla, A.; Wang, X. Y.; Chen, H.; Sistla, A.; Luu, T. C.; Tang, F.; Wei, J.; Tang, C. J. Med. Chem. 2003, 46, 1116.

(3) (a) Ding, K.; Lu, Y.; Nikolovska-Coleska, Z.; Wang, G.; Qiu, S.; Shangary, S.; Gao, W.; Qin, D.; Stuckey, J.; Krajewski, K.; Roller, P. P.; Wang, S. J. Med. Chem. 2006, 49, 3432. (b) Luk, K. C.; So, S. S.; Zhang, J.; Zhang, Z. WO Patent 2006136606, 2006; Chem. Abstr. 2006, 146, 100555.

(4) (a) Jiang, T.; Kuhen, K. L.; Wolff, K.; Yin, H.; Bieza, K.; Caldwell, J.; Bursulaya, B.; Wu, T. Y.-H.; He, Y. Bioorg. Med. Chem. Lett. 2006, 16, 2105. (b) Jiang, T.; Kuhen, K. L.; Wolff, K.; Yin, H.; Bieza, K.; Caldwell, J.; Bursulaya, B.; Tuntland, T.; Zhang, K.; Karanewsky, D.; He, Y. Bioorg. Med. Chem. Lett. 2006, 16, 2109.

(5) Ding, K.; Lu, Y.; Nikolovska-Coleska, Z.; Qiu, S.; Ding, Y.; Gao, W.; Stuckey, J.; Krajewski, K.; Roller, P. P.; Tomita, Y.; Parrish, D. A.; Deschamps, J. R.; Wang, S. J. Am. Chem. Soc. 2005, 127, 10130.

(6) Blakeney, J. S.; Reid, R. C.; Le, G. T.; Fairlie, D. P. Chem. Rev. 2007, 107, 2960.

(7) (a) Decaux, G.; Soupart, A.; Vassart, G. Lancet 2008, 371, 1624. (b) Shimazaki, T.; Iijima, M.; Chaki, S. Eur. J. Pharmacol. 2006, 543, 63. (c) Bernard, K.; Bogliolo, S.; Ehrenfeld, J. Br. J. Pharmacol. 2005, 144, 1037.

(8) (a) Holst, B.; Frimurer, T. M.; Mokrosinski, J.; Halkjaer, T.; Cullberg, K. B.; Underwood, C. R.; Schwartz, T. W. Mol. Pharm. 2009, 75, 44. (b) Tokunaga, T.; Hume, W. E.; Umezome, T.; Okazaki, K.; Ueki, Y.; Kumagai, K.; Hourai, S.; Nagamine, J.; Seki, H.; Taiji, M.; Noguchi, H.; Nagata, R. J. Med. Chem. 2001, 44, 4641.
(9) Sato, S.; Shibuya, M.; Kanoh, N.; Iwabuchi, Y. J. Org. Chem. 2009, 74, 7522.

(10) Altman, R. A.; Hyde, A. M.; Huang, X.; Buchwald, S. L. J. Am. Chem. Soc. 2008, 130, 9613; and references cited therein.

(11) Lesma, G.; Landoni, N.; Pilati, T.; Sacchetti, A.; Silvani, A. J. Org. Chem. 2009, 74, 4537.

(12) Ghosha, A. K.; Schiltz, G.; Perali, R. S.; Leshchenko, S.; Kay, S.; Walters, D. E.; Koh, Y.; Maedad, K.; Mitsuyad, H. Bioorg. Med. Chem. Lett. 2006, 16, 1869.

(13) Ben-Ishai, D.; Peled, N.; Sataty, I. Tetrahedron Lett. 1980, 21, 569 .

(14) Buchwald, S. L.; Hennessy, E. J. J. Am. Chem. Soc. 2003, 125, 12084; and references cited therein.

(15) Baroni, M.; Puleo, L. WO Patent 2009056707, 2009; Chem. Abstr. 2009, 150, 515023.

(16) Vazquez, E.; Payack, J. F. Tetrahedron Lett. 2004, 45, 6549.

(17) Burm, B. E. A.; Gremmen, C.; Wanner, M. J.; Koomen, G.-J. Tetrahedron 2001, 57, 2039.

(18) (a) Ling, K.-Q.; Sayre, L. M. Bioorg. Med. Chem. 2005, 13, 3543. (b) Alvarez, R. G.; Hunter, I. S.; Suckling, C. J.; Thomas, M.; Vitinius, U. Tetrahedron 2001, 57, 8581. (c) Van Deurzen, M. P. J.; van Rantwijk, F.; Sheldon, R. A. J. Mol. Catal. B: Enzym. 1996, 2, 33.

(19) (a) Movassaghi, M.; Schmidt, M. A.; Ashenhurst, J. A. Org. Lett. 2008, 10, 4009. (b) Walser, A.; Blount, J. F.; Fryer, R. I. J. Org. Chem. 1973, 38, 3077.

(20) (a) Ito, M.; Clark, C. W.; Mortimore, M.; Goh, J. B.; Martin, S. F. J. Am. Chem. Soc. 2001, 123, 8003. (b) Poriel, C.; Lachia, M.; Wilson, C.; Davies, J. R.; Moody, C. J. J. Org. Chem. 2007, 72, 2978.

(21) We also included the preparation of compound $\mathbf{3 c}$, which, strictly speaking, is not a heteroaryl derivative, but could serve to test the generality of the proposed methodology.

(22) Amat, M.; Hadida, S.; Sathyanarayana, S.; Bosch, J. J. Org. Chem. 1994, 59, 10.

(23) Yang, C.-G.; Liu, G.; Jiang, B. J. Org. Chem. 2002, 67, 9392.

(24) Kotha, S.; Lahiri, K.; Kashinath, D. Tetrahedron 2002, 58, 9633; and references cited therein.

(25) Lachia, M.; Poriel, C.; M, Z.; Slawin, A.; Moody, C. J. Chem. Commun. 2007, 286. 